\title{
O DESAFIO DA FORMAÇÃO DOS PROFESSORES PARA A EPT E PROEJA
}

\author{
LuCilia Regina de SouZa Machado*
}

\begin{abstract}
RESUMO: Este artigo analisa o desafio nacional da formação de professores para a Educação Profissional e Tecnológica (EPT), um aspecto crítico da expansão que vem se realizando nessa arena educacional e do atendimento das suas novas necessidades e demandas político-pedagógicas. Aborda aspectos históricos dessa formação, analisa dados estatísticos e examina criticamente dispositivos da legislação educacional brasileira. A grande diversidade do professorado da EPT, a dialética entre heranças recebidas e necessidades do presente e os novos ideários pedagógicos que esse campo educacional vem produzindo também compõem as categorias analíticas do estudo realizado. Ao final, são apresentados aspectos desse desafio, que o estudo realizado indicou ter caráter de urgência mais evidente.
\end{abstract}

Palavras-chave: Formação de professores. Educação Profissional e Tecnológica. PROEJA.

\section{THE CHALLENGE OF TEACHER TRAINING FOR EPT AND PROEJA}

ABSTRACT: This paper analyzes the Brazilian challenge of teacher training for Vocational and Technological Education (ЕPT), a critical aspect of the expansion that has been taking place in this educational arena and of the way its political and pedagogic needs and demands are met. It addresses historical aspects of this training, analyzes statistical data and critically examines the Brazilian educational legislation provisions. The great diversity of EPT teachers, the dialectics between past legacies and present needs and the new educational ideas that this educational field has been producing are also part of the analytical categories of the study. The conclusion presents aspects of the challenge that this study points out as more evidently urgent.

Key words: Teacher Training; Vocational and Technological Education. PROEJA.

* $\quad$ Doutora em Educação e professora do Mestrado Profissional em Gestão Social do Centro Universitário UNA. E-mail: 1smachado@uai.com.br 


\section{LE DÉFI DE LA FORMATION DES PROFESSEURS POUR L'EPT ET LE PROEJA}

RÉSUMÉ: Cet article analyse le défi de la formation de professeurs pour l'Éducation Professionnelle et Technologique (EPT) au Brésil, un aspect critique de l'expansion de cette modalité éducationnelle et de la réponse à ses nouvelles nécessités et demandes politiques et pédagogiques. Il aborde des aspects historiques de cette formation, analyse des données statistiques et examine de manière critique des dispositions de la législation scolaire brésilienne. La grande diversité des professeurs d'EPT, la dialectique entre l'héritage du passé et les besoins présents et les nouvelles idées pédagogiques que ce champ a produit intègrent les catégories d'analyse de la recherche réalisée. Les aspects les plus graves de ce défi sont présentés en conclusion.

Mots-clés: Formation des professeurs. Éducation Professionnelle et Technologique. PROEJA.

\section{Introdução}

A formação de professores para a Educação Profissional e Tecnológica (EPT) é decisiva para que a atual política de expansão, interiorização e democratização dessa modalidade educacional se efetive com qualidade social, produção de conhecimentos, valorização docente e desenvolvimento local, integrado e sustentável.

Este desafio, já histórico, revela-se mais crítico face à atual expansão da Rede Federal de Educação, Científica e Tecnológica a partir de 2005; às metas do Programa Nacional de Acesso ao Ensino Técnico e Emprego (pronatec) e Plano Nacional de Educação (PNE) 2011-2020; às novas necessidades político-pedagógicas vindas com o Programa Nacional de Integração da Educação Profissional à Educação Básica na Modalidade de Educação de Jovens e Adultos (PROEJA), o ensino médio integrado, Escola Técnica Aberta do Brasil (E-TEC), Programa Educação, Tecnologia e Profissionalização para Alunos com Necessidades Educacionais Especiais (TECNEP), EPT indígena e EPT quilombola.

Neste artigo, são analisados, criticamente, aspectos históricos da formação de professores para a EPT, dados estatísticos e dispositivos da legislação educacional brasileira sobre oferta de cursos e programas especiais de formação de professores para a educação básica; autorizações do exercício, a título precário, da função de professor nesse nível educacional; e morosidades na regulamentação das licenciaturas para a EPT, em desatenção ao que preceitua a Lei n. 9.394/96.

Elementos da diversidade docente na EPT quanto à trajetória acadêmica, formação pedagógica, inserções institucionais, condições e situações de trabalho; da dialética entre heranças recebidas e necessidades do presente; e dos novos ideários pedagógicos que esse campo educacional vem produzindo se agregam às categorias 
analíticas deste estudo. Ao seu final, o artigo destaca as questões que se revelaram de maior urgência.

\section{O contexto atual de um desafio já histórico}

Habitualmente vista como acessória à escolarização básica ou sua substituta, a EPT mais densa de ciência e cultura vê sua relevância elevada no rastro da valorização do trabalho qualificado pelas economias em crescimento, pela atual dinâmica da competição capitalista e em propostas de desenvolvimento nacional, soberano, melhor distributivo social, econômica e ambientalmente. Poucos se lembram, porém, de um flanco crítico: a sustentabilidade pedagógica da oferta de EPT por quadros docentes formados e valorizados adequadamente.

Ainda se recrutam professores para a EPT fiando-se apenas em formação específica e experiência prática, crendo que a constituição da docência se dará pelo autodidatismo. Contudo, pela Lei n. 9.394/96, artigo 62, "a formação de docentes para atuar na educação básica far-se-á em nível superior, em curso de licenciatura, de graduação plena, em universidades e institutos superiores de educação (...)" (Brasil, 1996).

Cursos de educação profissional técnica de nível médio (ЕPTNM) fazem parte da educação básica. Os de formação inicial e continuada (FIC) também, pois integram itinerários formativos, são passíveis de certificação e de validação para fins de aproveitamento de estudos. Especialistas em educação, no desempenho de atividades educativas (diretores de unidades escolares, coordenadores e assessores pedagógicos), compõem, igualmente, o magistério desses cursos ( $\S 2^{\circ}$ do art. 67, Lei n. 9.394/96). Outro era o entendimento do Decreto n. 2.208/97, ao ditar organização curricular própria da educação profissional de nível técnico, independente do ensino médio (art. 5으. Revogada pelo Decreto n. 5.154/04, a Lei n. 11.741/08 reafirmou o princípio da integração a reger as ações da educação profissional técnica de nível médio, da educação de jovens e adultos e da EPт (Brasil, 2008).

O cumprimento do artigo 62 da Lei n. 9.394/96, porém, ainda não chegou às estatísticas. A Sinopse do Professor de 2009 contabilizou 58.898 professores em atividade na educação profissional técnica de nível médio. Destes, apenas 59,0\% possuíam licenciatura; $11,8 \%$ sem curso superior concluído; $11,7 \%$ com somente o ensino médio e 0,07\%, o ensino fundamental (Brasil, 2009). Esta situação encontrou eco no revogado Decreto n. 2.208/97:

Art. 9o - As disciplinas do currículo do ensino técnico serão ministradas por professores, instrutores e monitores selecionados, principalmente, em função de sua experiência profissional, que deverão ser preparados para o magistério, previamente ou em serviço, através de cursos regulares de licenciatura ou de programas especiais de formação pedagógica. (Brasil, 1997. Grifos meus) 
Os sistemas de ensino dos estados da Federação têm autorizado o exercício, a título precário, da função de professor na educação básica, alegando a falta de professores habilitados. Em Minas Gerais, a Resolução CEe/MG n. 397, de 1994 (!) é o instrumento legal utilizado pela Secretaria de Estado da Educação para essa autorização, cuja validade de um ano é suscetível de "ser renovada anualmente, enquanto persistir na localidade a falta ou insuficiência de professor legalmente habilitado" (art. $2^{\mathrm{o}}$ ). A autorização e sua renovação são da competência do órgão regional de ensino (art. $\left.3^{\circ}\right)$, responsável pelos assuntos de inspeção escolar. A principal condição exigida é a prova da qualificação do interessado para o conteúdo específico que pretende ministrar. Entre os critérios de qualificação constam, por exemplo, a prova de conclusão de curso superior, de cujo currículo conste a disciplina a ser lecionada, e a prova de matrícula com frequência em curso superior, no qual já tenha concluído o estudo da disciplina ou disciplina afim à que pretende lecionar. Mas, caso persista a alegação de que faltam professores para conteúdos da formação especial (conteúdos técnicos), é aceito, como critério de qualificação, o diploma de curso de ensino médio, da mesma habilitação ou de habilitação afim ao curso para o qual se destina a contratação! (Minas Gerais, 1994).

O professorado da EPT apresenta, portanto, grande diversidade em matéria de formação pedagógica. A essa heterogeneidade se acrescentam outras diferenças: de campo científico, tecnológico e cultural de origem, espaços institucionais de atuação, alunado, formas de recrutamento (concursos públicos de provas e títulos, processos seletivos simples ou escolha pessoal do diretor ou coordenador), regime de contratação (por jornada parcial ou integral, por hora-aula), tipos de vínculo empregatício (maior ou menor estabilidade), condições de trabalho e de remuneração e sentido que a docência tem para o professor (atividade de trabalho principal ou complementar). Logo, se produzem diferentemente as identidades profissionais, a socialização profissional, a concepção da profissão, as práticas profissionais e os processos de profissionalização (Souza, 2005).

Dados da Sinopse do Professor (Brasil, 2009): mais da metade (33.100 ou 56,2\%) dos 58.898 professores em atividade na EPTNM tinha vínculo apenas com instituições privadas, rede que se destaca pela grande heterogeneidade de situações e condições de trabalho; $16.943(28,8 \%)$ professores ligados somente a instituições estaduais, também com grandes diversidades institucionais e contratuais; $6.453(11,0 \%)$ docentes (com atuação na EPTNM) contratados exclusivamente pela rede federal de educação profissional, científica e tecnológica, um universo mais homogêneo, mas que também tem suas clivagens.

A heterogeneidade institucional, situacional e de trajetória profissional do professorado da ЕРт é um dado importante a ser considerado pelas políticas de formação inicial e continuada destinadas aos docentes, sobretudo quando se pensa que, 
em vista das atuais questões relativas ao mundo do trabalho, à dinâmica tecnológica e de produção de conhecimentos, à diversidade cultural, à sustentabilidade ambiental, à vida em sociedade, o exercício dessa docência se tornou mais complexo, exigindo-se das práticas pedagógicas maior coerência, consistência, diálogo, participação.

Acrescentam-se a esse quadro as consequências, internas e para as outras redes, da enorme expansão da Rede Federal de Educação Profissional, Científica e Tecnológica, iniciada em 2005, quando ainda dispunha de apenas 140 escolas, amealhadas desde 1909, em quase cem anos de história. Dados divulgados amplamente pelo Ministério da Educação (MEC) e pela Presidência da República permitem traçar o seguinte quadro: criação, entre 2005 e 2010, de 214 novas unidades escolares graças ao investimento federal de $R \$ 1,1$ bilhão; previsão de conclusão de mais 81 unidades para até o fim de 2012 e de mais 120 unidades entre 2013 e 2014, estas com o apoio do pronatec. Este programa, lançado em 28/04/11, de iniciativa da Presidência da República, se propõe a qualificar oito milhões de pessoas nos próximos quatro anos, por meio de cursos técnicos e de formação inicial e continuada, e está em apreciação sob regime de urgência pelo Congresso Nacional. Ao término de 2014, calcula-se que a rede federal terá 555 unidades, 415 a mais do número registrado em 2005. Isso significa crescer, em número de escolas, quatro vezes em nove anos. As vagas chegarão a 600 mil em 2014. Em 2005, as matrículas não passavam de 173 mil. Das 420 mil matrículas ofertadas por esta rede em 2011, 301 mil são de cursos técnicos e de formação inicial e continuada (71,7\%). As demais matrículas (118 mil) se distribuem pelos cursos de licenciatura, bacharelado, pós-graduação e superiores de tecnologia. Atualmente, o número de docentes na rede federal chega a 19,5 mil. A expansão implicou a contratação de 12,5 mil professores. Isso significa crescimento do corpo docente em $78,9 \%$ nos últimos seis anos.

Em debate sobre formação de professores para a EPT, realizado pelo MEC em Brasília, em 2006, Denio Rebello Arantes, atual reitor do Instituto Federal do Espírito Santo e vice-presidente do Conselho Nacional das Instituições da Rede Federal de Educação Profissional, Científica e Tecnológica, expôs sua preocupação:

\footnotetext{
Hoje está entrando uma leva enorme de professores que tem mestrado e doutorado, mas, por outro lado, muitos deles nunca tiveram uma atuação profissional anterior. Para muitos, essa é a primeira vez que estão atuando profissionalmente e, vejam a contradição, eles vêm para o CEFET para dar aula de educação profissional. Temos encontrado problemas bastante sérios e não apenas de natureza pedagógica. Recentemente, depois de uma longa discussão, um desses nossos novos professores diz: realmente a gente não está sabendo formar técnicos. Se você pedir para ele formar um graduado, ele sabe, agora se você pedir para formar um técnico, ele não sabe.

(...) os professores novos estão mais preparados em termos de tecnologia, porque estão mais atualizados, e, por um outro lado, uma parte deles não conhece nada do mundo do trabalho. Os "professores antigos" conheciam menos de tecnologia, mas sabiam muito do mundo do trabalho. (INEP, 2008, p. 244 e 246)
} 
Ou seja, o desafio da formação de professores para a EPT manifesta-se de vários modos, principalmente quando se pensa nas novas necessidades e demandas político-pedagógicas dirigidas a eles: mais diálogos com o mundo do trabalho e a educação geral; práticas pedagógicas interdisciplinares e interculturais; enlaces fortes e fecundos entre tecnologia, ciência e cultura; processos de contextualização abrangentes; compreensão radical do que representa tomar o trabalho como princípio educativo; perspectiva de emancipação do educando, porquanto sujeito de direitos e da palavra. Na maneira de compreender a proposta de ensino médio integrado, por exemplo, muitos professores se valem, erroneamente, da concepção da antiga Lei n. 5.492/71 de composição curricular por justaposição da parte propedêutica do ensino médio com alguma habilitação profissional.

Provavelmente, esta era a referência que orientava grande parte dos 20.593 professores que estavam atuando no ensino médio integrado em 2009 (apenas nessa modalidade ou acumulando experiências na concomitante e na subsequente) (Brasil, 2009). Contudo, pôr em prática currículos integrados demanda formação docente continuada, de modo a assegurar o necessário trabalho coletivo e colaborativo dos professores de conteúdos da educação geral e profissional; a compreensão de como desenvolver os princípios educativos do trabalho, da ciência, da tecnologia e da cultura; o diálogo entre teoria e prática; o pensar e o agir na lógica da interdisciplinaridade; a sintonia com o desenvolvimento tecnológico e o contexto socioeconômico e ambiental. No caso do PROEJA, a complexidade do desenho curricular e da prática didático-pedagógica é ainda maior, pois envolve a educação geral do ensino médio e fundamental, conteúdos especiais da ETPNM e da FIC e abordagens da educação de jovens e adultos.

A Ерт a distância também representa um novo e importante desafio à formação de professores, por sua especificidade e números da expansão prevista. O Sistema Escola Técnica Aberta do Brasil (E-TEC), criado em 2007, registra 30 mil alunos, 396 polos e 41 instituições federais e estaduais aderentes em 2011. Porém, a meta do PRONATEC, segundo O MEC, é de multiplicar por nove o alunado da EPT a distância até o fim de 2014, chegando a 270 mil.

Os objetivos do PRONATEC são expandir, interiorizar e democratizar a oferta de cursos técnicos e de formação inicial e continuada, beneficiando oito milhões de estudantes e trabalhadores até 2014. Sem uma política de formação de professores para a ЕРт de expressividade correspondente, tais objetivos se efetivarão? A análise do texto do Projeto de Lei (PL) n. 1.209/11 (Brasil, 2011), que institui aquele programa, não se refere a esta questão. $\mathrm{O}$ foco do documento se dirige à ampliação de vagas e das oportunidades educacionais dos trabalhadores mediante a oferta de bolsa-formação; à assistência e transferência de recursos financeiros às instituições de Ерт das redes públicas estaduais e municipais, ou dos serviços nacionais 
de aprendizagem correspondentes aos valores das bolsas-formação e à melhoria da rede física e expansão da rede federal. É possível que a formação de professores para a ЕРт esteja subentendida nas pretensões do programa de apoio técnico e de melhoria da qualidade do ensino médio público, mas o texto não faz esse esclarecimento.

Interiorizar e democratizar a oferta também significa expandir com qualidade e atender as normas de regulação educacional traduzidas pelos catálogos nacionais de cursos (técnicos e superiores de tecnologia); pela mudança da sistemática de organização da oferta da EPT (antes, por áreas profissionais e, agora, por eixos tecnológicos); pela constituição das matrizes curriculares a partir de elementos do núcleo politécnico comum; pela necessária interação entre educação, ciência, tecnologia e cultura (Machado, 2010).

No final de 2010, o governo federal encaminhou ao Congresso Nacional uma proposta de projeto de lei para o PNE 2011-2020, contendo vinte metas educacionais a serem cumpridas até o final da presente década. Identificado como PL n. 8.035/10, sua Meta 3 propõe "universalizar, até 2016, o atendimento escolar para toda a população de 15 a 17 anos e elevar, até 2020, a taxa líquida de matrículas no ensino médio para $85 \%$, nesta faixa etária" (Brasil, 2010). Entre as estratégias previstas para o alcance destes resultados, a de número 3.4 aponta para a "expansão das matrículas de ensino médio integrado à educação profissional, observando-se as peculiaridades das populações do campo, dos povos indígenas e das comunidades quilombolas", decisão política importante que requer, contudo, atenção pedagógica diferenciada, incorporação efetiva da diversidade sociocultural do alunado e, obviamente, formação docente, inicial e continuada, condizente.

A Meta 10 do PL 8.035/10 fixa a oferta de, "no mínimo, 25\% das matrículas de educação de jovens e adultos na forma integrada à educação profissional nos anos finais do ensino fundamental e no ensino médio". Entre as estratégias previstas para tal, duas fazem referência explícita à promoção da formação continuada de docentes: a 10.5 e a 10.8 (Brasil, 2010).

Com a Meta 11, o governo federal projetou alcançar a duplicação das matrículas da educação profissional técnica de nível médio até o final da década, contando para isso com a atuação dos Institutos Federais de Educação, Ciência e Tecnologia, das redes públicas estaduais de ensino, das entidades privadas de formação profissional vinculadas ao sistema sindical. Nas estratégias definidas para a concretização dessa meta, não se menciona a formação de professores. É na Estratégia 12.4 da Meta 12 que aparece o propósito de promover "a oferta de educação superior pública e gratuita prioritariamente para a formação de professores para a educação básica, sobretudo nas áreas de ciências e matemática, bem como para atender o déficit de profissionais em áreas específicas". A Meta 15 pretende "que todos os professores da 
educação básica possuam formação específica de nível superior, obtida em curso de licenciatura na área de conhecimento em que atuam" e propõe esforço conjunto dos entes federativos para garanti-la. Nesse sentido, são estabelecidas linhas de atuação: elaboração de plano estratégico, criação de condições especiais de financiamento estudantil, programa de iniciação à docência, plataforma eletrônica específica, institucionalização da política de formação e valorização dos profissionais da educação, programas específicos para formação de professores para as populações do campo, comunidades quilombolas e povos indígenas, reforma curricular dos cursos de licenciatura. Resgata-se, inclusive, a alternativa de cursos e programas especiais de formação destinados aos "docentes com formação de nível médio na modalidade normal, não licenciados ou licenciados em área diversa da de atuação docente, em efetivo exercício" (Estratégia 15.10) (Brasil, 2010).

\section{Cursos e programas especiais de formação de professores}

A ideia de curso especial marcou a história da formação de professores para a EPT, no Brasil, iniciada com a criação da Escola Normal de Artes e Ofícios Wenceslau Braz, em 1917. Esta instituição foi criada com base no pressuposto de que a formação de professores para a educação profissional seria de espécie diferente. As Leis Orgânicas de Ensino (década de 1940), tendo incorporado a índole corporativista do Estado Novo e em correlação com a criação do Sistema S, radicalizaram esse conceito: os cursos de formação docente para os ensinos industrial, comercial, agrícola e normal deveriam ser "apropriados", ou a radice, sob a feição peculiar de cada um desses domínios da divisão técnica do trabalho. Oficialmente, essa norma segmentadora perdurou para muito além do fim do Estado Novo, pois o plano unificador da formação de professores para disciplinas especializadas do ensino médio só foi estabelecido em 1971, com o Parecer CFE n. 111, no contexto da Lei n. 5.692/71, que instituiu a profissionalização universal e compulsória no ensino médio. É importante dizer que a LDв de 1961 (Lei n. 4.024), de modo conservador, concebeu, no seu artigo 59, dois caminhos diferentes e separados de formação de professores: os docentes para o ensino médio geral, inclusive para o curso normal, seriam formados em faculdades de Filosofia, Ciências e Letras e os de disciplinas específicas de ensino médio técnico em cursos especiais de educação técnica (Machado, 2008a; 2008b).

Essa noção de cursos especiais de educação técnica ganhou uma fisionomia marcante: em 19 de julho de 1971, na véspera do lançamento da Lei n. 5.692/71, foi publicada a Portaria n. 432 e instituídos dois tipos de cursos especiais, identificados como emergenciais: os Esquemas I e II. De nível superior, conferiam diploma de Licenciatura, e seus resquícios podem ser encontrados na Resolução CNE/CP n. 2/97, 
que serve atualmente para perenizar a solução emergencial que foi encontrada à época para formar professores para a ЕРT.

O Esquema I, de complementação pedagógica, carga de 600 horas, destinava-se aos diplomados em curso superior relacionado à habilitação pretendida e se compunha das disciplinas: Estrutura e Funcionamento do Ensino de $2^{\mathrm{o}}$ grau, Psicologia da Educação, Didática e Prática de Ensino, esta com 290 horas. O Esquema II, para técnicos de nível médio formados na área da habilitação requerida, com duração entre 1.080 e 1.480 horas, abrangia conteúdos propedêuticos, pedagógicos e da área técnica.

A Lei n. 9.394/96 não incorporou a opção do Esquema II, mas conservou a prerrogativa dos diplomados em nível superior, sem licenciatura e interessados em atuar na educação básica, de cursarem programas de formação pedagógica (art. 63, inciso II). O Parecer CNE/CP n. 04/97, que resultou na Resolução CNE/CP n. 02/97, regulamentadora desse artigo, previu o estabelecimento de normas especiais à preparação de professores para as disciplinas de cunho técnico, mas esse detalhamento não chegou ao texto dessa Resolução, nem foi objeto de dispositivos complementares. Também permanece como letra morta a decisão, que consta desse texto, de, no prazo de cinco anos, submeter o que nele foi estabelecido à avaliação do Conselho Nacional de Educação (CNE) (§ único do art. 11).

Pela Resolução CNE/CP n. 2/97, os programas especiais podem ser desenvolvidos em 540 horas (mínimo) e, mesmo assim, o certificado obtido se equivale ao diploma de licenciatura plena, com validade em todo o território nacional e caráter definitivo. Destas horas, 300 se destinam a atividades práticas. Ou seja, podem ser oferecidos programas com apenas 240 horas de formação teórica. A Resolução traz diretrizes importantes com relação ao tratamento dos conhecimentos e habilidades, que devem ser amplos e de forma integrada; à estruturação do currículo em núcleos (contextual, estrutural e integrador), que aparecem bem delimitados e concebidos; à necessidade de garantir estreita e concomitante relação entre teoria e prática e à proibição da oferta da parte prática exclusivamente ao final do programa. Determina, ainda, que seja concedida ênfase à metodologia de ensino específica da habilitação pretendida. Questiona-se, contudo, se tais diretrizes, embora pertinentes, encontram sustentáculo na carga horária mínima aprovada ou se vêm realmente sendo obedecidas.

Em 2006, foi aprovado o Parecer CNE/CP n. 5, destinado a apreciar a Indicação CNE/CP n. 2/2002 sobre as Diretrizes Curriculares Nacionais para Cursos de Formação de Professores para a Educação Básica. Esse texto opinou favoravelmente à manutenção dos programas especiais de formação pedagógica de professores, mas indicou a necessidade de revogação da Resolução CNE/CP n. 2/97 e da sua regulação por novos 
padrões, em conformidade com as Diretrizes Curriculares Nacionais para a Formação de Professores (Parecer CNE/CP n. 9/01 e Resolução CNE/CP n. 1/02) e campos de conhecimento pertinentes, de modo a conferir habilitações correspondentes com o curso de graduação originalmente realizado. Entendeu, ainda, ser necessário elevar a carga horária mínima destes programas para 800 horas, reservando, no mínimo, 300 horas para estágio supervisionado e o restante às demais atividades formativas. Indicou critérios para autorização e reconhecimento desses programas. Com base no estudo realizado, a Comissão, que assina o Parecer CNE/CP n. 5/06, apresentou um Projeto de Resolução contendo normas sobre a matéria e a proposta de revogação das Resoluções CNE/CP n. 2/97 e 2/02. Este Projeto, contudo, não foi à aprovação.

Além dos aspectos mencionados pela Comissão, há outros relativos à da gestão desses programas que merecem a atenção dos sistemas de ensino. Liberalesso (2010) comenta que nem sempre os que concebem as propostas desses cursos participam da sua execução; que os programas, geralmente, são realizados com recursos extraorçamentários e por empresas participantes de licitações, que, às vezes, contratam profissionais sem experiência em educação profissional e/ou em formação de professores para neles atuarem como docentes.

\section{Licenciaturas para a EPT}

A Lei n. 5.540/68 (Reforma Universitária) estabeleceu, no seu artigo 30, que também a formação dos professores para as disciplinas técnicas do ensino de segundo grau deveria ser feita em cursos superiores. Nesse sentido, o Parecer cFe n. 479/68 se ocupou de orientações sobre currículos mínimos e duração dos cursos, com base nas normas já adotadas pelo Parecer CFE n. 262/62. Porém, o subterfúgio da habilitação mediante exame de suficiência, paliativo aceito pelo Decreto-Lei n. 464/69, que estabeleceu normas complementares à Lei n. 5.540/68, contribuiu para que o referido artigo 30 fosse deixado para trás.

Também foi mal sucedido o intento do Conselho Federal de Educação (СFE) de determinar a transformação dos cursos de Esquemas I e II, concebidos inicialmente como provisórios e emergenciais, em licenciaturas plenas para a parte de formação especial do $2^{\circ}$ grau. A Resolução CFE n. 3/1977 estabeleceu o prazo máximo de três anos para essa adaptação. Não tendo obtido êxito, o CFE manteve a coexistência das duas opções (Resolução n. 7/82) para justificar, em 1989, no Parecer n. 632/89, a continuidade dos Esquemas:

A Resolução (03/77) não teve ressonância nos meios universitários não só porque admitiu a permanência dos Esquemas I e II, como porque aqueles esquemas se mostraram mais eficazes para a formação dos professores. Não há dúvida de que 
a utilização de profissionais já habilitados para o ensino de disciplinas próprias de sua atividade profissional melhor se recomenda que a tentativa de habilitar professores sem qualquer experiência de atividade profissional. De sorte que, gradativamente, mesmo instituições que instalaram as licenciaturas nos termos da Resolução n. 03/77 vêm desativando esses cursos (...). (CFE, 1989)

Esse modo de pensar explica por que o artigo 62 da Lei n. 9.394/96 permanece retórico quanto à formação de professores para a EPT e o não desdobramento resolutivo do Parecer CNE/CP n. 5/2006, que propôs a revogação da Resolução CNE/CP n. 2/97, novas normas para programas especiais, licenciaturas organizadas em habilitações especializadas por componente curricular ou abrangentes por campo de conhecimento e com carga horária mínima de 2.800 horas, das quais 300 seriam para estágio supervisionado.

Em 2008, foram realizadas, em todo o território nacional e sob a coordenação das instituições da Rede Federal de Educação Profissional, Científica e Tecnológica, 47 audiências públicas para discutir a proposta de licenciaturas para a EPT. O documento debatido (Machado, 2008b), para cujo aperfeiçoamento essas audiências ofereceram sugestões, resultou de estudos e discussões promovidos pela SETEC/MEC. Foram convidados à discussão todos os segmentos interessados: Ministério Público Federal, faculdades e universidades, secretarias estaduais e municipais de educação, instituições de ЕPт pública e particular, Sistema $S$, sindicatos de professores, conselhos estaduais e municipais de educação e de defesa de direitos sociais, conselhos profissionais. $\mathrm{O}$ cNE recebeu o documento final desse processo e ainda está estudando a matéria.

A SETEC/MEC vem incentivando as instituições federais a desenvolver licenciaturas para a EPT a partir das seguintes referências: educação como direito e afirmação de um projeto societário de emancipação social; compromisso com a escola pública; conexões entre a formação de professores para a educação básica e a formação de professores para a educação profissional; diálogo com as políticas sociais e econômicas, com destaque para aquelas com enfoques locais e regionais; incorporação dos princípios educativos do trabalho, da ciência, da tecnologia e da cultura e suas interações; integração entre ensino, pesquisa e extensão; sintonia com as demandas sociais, econômicas e culturais; incorporação da diversidade cultural; sustentabilidade ambiental; ética da responsabilidade e do cuidado; o professor como pesquisador de sua própria prática pedagógica.

\section{Formação de professores para o PROEJA}

O PROEJA foi criado pelo governo federal (Decreto n. 5.478/05), motivado a ampliar, no sistema público de ensino, as ações e vagas destinadas à educação de jovens e adultos (EJA). Nasceu circunscrito às instituições federais de EPT, para oferecer 
ensino médio articulado como a Fic e com a EPTNM. Em 2006, novas diretrizes (Decreto n. 5.840/06) alargaram sua abrangência, incluindo o ensino fundamental da EJA, instituições públicas dos sistemas de ensino estaduais e municipais e entidades privadas nacionais de serviço social, aprendizagem e formação profissional vinculadas ao sistema sindical (Sistema S).

A setec/Mec, no contexto de uma ampla política de incentivo e apoio ao PROEJA, considerou os grandes desafios políticos, epistemológicos, pedagógicos e infraestruturais nele envolvidos e abriu quatro frentes de formação continuada de professores.

A primeira, a Especialização PROEJA, é destinada a docentes e gestores e à produção de conhecimentos por meio da reflexão coletiva e do exercício de práticas, visando à concretização da concepção inovadora deste Programa. A Rede Federal de Educação Profissional, Científica e Tecnológica foi estimulada a oferecer esse curso, contando com a contrapartida financeira e a orientação técnica da SETEC/MEC. Sua formatação inclui questões de implementação, organização, acompanhamento e controle do pROEjA e do desenvolvimento de currículos integrados, envolvendo as interseções entre educação geral e profissional no campo da EJA e as perspectivas da inclusão educacional e da educação integral.

Este curso visa a motivar os professores a enfrentar o desafio do desenvolvimento teórico e prático dos fundamentos deste programa, particularmente o trabalho como princípio educativo, nas suas interações com a ciência, a tecnologia, a educação e a cultura, e o desenvolvimento de aprendizagens significativas por meio da interação do conhecimento sistematizado com os do educando, construídos a partir de sua realidade existencial.

15 polos ofereceram a Especialização PROEJA em 2006; 21 em 2007 e 33 em 2008 e 2009, os quais, em quatro anos, receberam 11.433 matrículas de educadores, gestores e técnicos administrativos: 1.400 em 2006, 3.450 em 2007, 3.794 em 2008 e 2.789 em 2009, implicando o repasse pela setec-mec de $\mathrm{R} \$ 31$ milhões (Brasil, 2011a).

A segunda frente de formação de profissionais para o PROEJA, igualmente lançada em 2006, consiste no Programa de Apoio ao Ensino e à Pesquisa Científica e Tecnológica em Educação Profissional Integrada à Educação de Jovens e Adultos (PROEJA-CAPES/SETEC). Este Programa - proposto e aprovado no âmbito do Programa Nacional de Apoio ao Ensino e à Pesquisa em Áreas Estratégicas (PRONAP) - se voltou especificamente à formação pós-graduada stricto sensu e ao desenvolvimento de pesquisas, produção de conhecimentos, intercâmbio acadêmico, formação de parcerias e consórcios interinstitucionais, estruturação e aperfeiçoamento de estratégias educacionais e diálogo educacional entre profissionais da educação básica, EPT e ejA. Dos temas tratados constam: análise e avaliação de políticas públicas; estudo 
de cenários regionais; integração de currículos da educação geral, educação profissional e EJA; historicidade e contextos sociais; diversidade sociocultural; formação humana e produção de identidades sociais; relação entre educação e trabalho; formação inicial e continuada de professores; práticas de ensino; ciência e tecnologia; arranjos produtivos, cultura e organização social locais; desenvolvimento humano sustentável; economia solidária, produção comunitária; educação do campo.

A terceira frente se refere à realização de Cursos de Formação Continuada em PROEJA com cargas horárias de 120 a 240 horas, destinados aos profissionais de escolas federais e estaduais. Os investimentos nestes cursos, em 2007 e 2008, chegaram a $\mathrm{R} \$ 8,5$ milhões. Os Diálogos PROEJA correspondem à quarta frente voltada à formação de docentes para este Programa e se caracterizam por encontros microrregionais realizados pelas instituições federais, envolvendo equipes técnicas e docentes e visando à troca de conhecimentos e experiências focalizados nos desafios encontrados e na busca conjunta de soluções. Em 2008, foram realizados 14 Diálogos PROEJA (Brasil, 2011a). Há, ainda, a produção de materiais destinados à formação docente, atendendo às especificidades: Proeja Técnico/Ensino Médio, Proeja Formação Inicial e Continuada/Ensino Fundamental e Proeja Indígena/Educação Profissional Integrada à Educação Escolar Indígena.

Essas ações de formação continuada têm estimulado a compreensão e a prática de conceitos como: gestão participativa; trabalho coletivo colaborativo; engajamento dos professores no projeto político-pedagógico escolar; articulação em torno de problemas concretos; identificação do professor com a EJA; sistematização das experiências e práticas pedagógicas desenvolvidas; diálogo educacional; diversidades culturais; resgate dos saberes profissionais não codificados.

\section{Considerações finais}

Como se viu anteriormente, várias são as questões inerentes ao desafio atual da formação inicial e continuada de professores para a EPT, no Brasil. A título de síntese, sem prejuízo a outras igualmente relevantes, destacam-se sete urgências que emergiram do estudo realizado:

1. Garantir a sustentabilidade pedagógica e de gestão à expansão, interiorização e democratização da oferta de cursos técnicos e de formação inicial e continuada - com destaque para as modalidades ensino médio integrado, PROEJA, a distância, EPT inclusiva, EPT do campo, indígena e quilombola - urgências que emergem da enorme expansão da Rede Federal de Educação Profissional, Científica e Tecnológica, iniciada em 2005, e das elevadas metas previstas pelo PRONATEC e pelo PNE 2011-2020. 
2. Revogar os instrumentos legais que possibilitam autorizações do exercício, a título precário, da função de professor na educação básica.

3. Revogar a Resolução CNE/CP n. 2/97 e regulamentar a oferta de licenciaturas para a ЕРт com os formatos que compatibilizem especificidades de trajetórias acadêmicas do professorado, observando-se em todos eles os princípios que orientam a base comum de organização curricular dos cursos de formação dos profissionais da educação no Brasil e a perspectiva de uma política nacional unitária de magistério.

4. Oferecer licenciatura a um grande número de professores sem a habilitação requerida pelo artigo 62 da Lei n. 9394/96, que estão em atividade na EPт. Pelos dados da Sinopse do Professor de 2009, produzida pelo INEP/ MEC, esse contingente representava $41,0 \%$ do total dos professores ativos, proporção com tendência a crescimento em vista da grande expansão de vagas e de cursos já observada e do estado letárgico em que a formação de professores para a EPT encontra-se em todo o país.

5. Continuar, aprofundar e expandir a política de formação continuada de apoio ao prozja e, nos seus moldes, desenvolver ações semelhantes voltadas ao ensino médio integrado regular, às especificidades da EPT por eixos tecnológicos, à organização curricular por núcleos politécnicos comuns, à EPT a distância, à EPT do campo, à EPT de povos indígenas, à EPT de comunidades quilombolas, à EPT inclusiva (Programa TECNEP).

6. Promover pesquisas e a produção de conhecimentos no campo da EPT, sobretudo com a participação dos próprios professores a ela dedicados. Entre os temas, podem ser citados: a atividade do professor de EPT; práticas pedagógicas; saberes profissionais não codificados; avanços didáticos e pedagógicos que se fazem necessários; trabalho, ciência, tecnologia e cultura como princípios educativos; organização curricular por eixos tecnológicos, núcleos politécnicos comuns; diálogos com as políticas sociais e econômicas, com o mundo do trabalho, entre a teoria e a prática; interação e integração com a educação geral; interdisciplinaridade na EPT; diversidades culturais e EPT; processos de contextualização; enfoques locais e regionais; sintonia com as demandas sociais, econômicas e culturais; sustentabilidade ambiental; ética da responsabilidade e do cuidado; gestão participativa; trabalho coletivo e colaborativo; integração entre ensino, pesquisa e extensão; EPT a distância e EPT inclusiva.

7. Promover o fortalecimento da identidade profissional dos professores da EPT por meio de políticas de formação, valorização e carreira docente, que levem à diminuição da grande heterogeneidade desse professorado, fator 
que dificulta seu processo de profissionalização. Desenvolver formação inicial e continuada que contribua para dar o sentido de pertencimento ao grupo social dos professores da EPT e que dialogue com as expectativas, realidades e desafios do trabalho da docência neste campo educacional. Estimular o conhecimento por parte dos professores dos determinantes internos e externos à sua atuação profissional, das condições da sua materialidade, das crenças e valores em disputa, dos diferentes saberes que precisam convocar, das especificidades da profissão, das necessidades do desenvolvimento profissional e de como fomentá-lo.

\section{Referências}

BRASIL. Decreto n. 2.208, de 17 de abril de 1997. Regulamenta o $§ 2$ do art. 36 e os arts. 39 a 42 da Lei n. 9.394, de 20 de dezembro de 1996, que estabelece as Diretrizes e Bases da Educação Nacional. Diário Oficial da União, Brasília, DF, 18 abril 1997. Disponível em: <http://www.planalto.gov.br/ccivil_03/decreto/D2208.htm>. Acesso em: 19 jun. 2011.

BRASIL. Lei n. 9.394, de 20 de dezembro de 1996. Estabelece as Diretrizes e Bases da Educação Nacional. Diário Oficial da União, Brasília, DF, 23 dez. 1996. Disponível em: $<$ http://www.planalto.gov.br/ccivil_03/Leis/L9394.htm>. Acesso em: 21 jun. 2011.

BRASIL. Lei n. 11.741, de 16 de julho de 2008. Altera dispositivos da Lei n. 9.394, de 20 de dezembro de 1996, que estabelece as diretrizes e bases da Educação Nacional... Diário Oficial da União, Brasília, DF, 17 jul 2008. Disponível em: <http://www.planalto. gov.br/ccivil_03/_Ato2007-2010/2008/Lei/L11741.htm>. Acesso em: 21 jun. 2011.

BRASIL. Ministério da Educação. Portal do MEC. Brasília, DF: MEC, 2011. Disponível em: <http://portal.mec.gov.br/index.php?option=com_content\&view=article\&id=12 288\&Itemid=562>. Acesso em: 14 jun. 2011.

BRASIL. Ministério da Educação. Conselho Federal de Educação. Parecer n. 632/89. Disponível em: <http://www.dominiopublico.gov.br/download/texto/cd003520.pdf>. Acesso em: 15 mai. 2011.

BRASIL. Ministério da Educação. Conselho Nacional de Educação. Resolução CNE/ CP n. 02/97. Dispõe sobre os programas especiais de formação pedagógica de docentes [...]. Disponível em: <http://portal.mec.gov.br/setec/arquivos/pdf/RCNE_CEB02_ 97.pdf $>$. Acesso em: 24 jun. 2011.

BRASIL. Ministério da Educação. Instituto Nacional de Estudos e Pesquisas Educacionais (INEP). Formação de professores para ерт: Brasília, 26, 27 e 28 de setembro de 2006. Brasília, DF: INEP, 2008. 304p. 
BRASIL. Ministério da Educação. Instituto Nacional de Estudos e Pesquisas Educacionais (INEP). Sinopse do Professor: 2009. Brasília, DF: MEC/INEP, 2009. Disponível em: $<$ http://portal.inep.gov.br/basica-censo-escolar-sinopse-sinopse> Acesso em: 21 jun. 2011.

BRASIL. Projeto de Lei n. 1209, de 2011. Institui o Programa Nacional de Acesso ao Ensino Técnico e Emprego - pronatec [...]. Brasília, DF, 2011b. Disponível em: $<$ http://www.planalto.gov.br/ccivil_03/Projetos/PL/2011/msg112-28ABR2011.htm>. Acesso em: 16 jun. 2011.

BRASIL. Projeto de Lei n. 8035, de 2010. Aprova o Plano Nacional de Educação para o decênio 2011-2020 e dá outras providências. Disponível em: <http://www.camara. gov.br/sileg/integras/831421.pdf>. Acesso em: 23 jun. 2011.

LIBERALESSO, R. Formação pedagógica para a docência na EPT: desafios e possibilidades. In: SEMINÁRIO NACIONAL DE EPT, 2., 2010, Belo Horizonte. Anais... Belo Horizonte: CEFET-MG, 2010. p. 1-11. Disponível em: <http://www.senept.cefetmg.br/ galerias/Anais_2010/Artigos/GT8/FORMACAO_PEDAGOGICA.pdf $>$. Acesso em: 13 jun. 2011.

MACHADO, L. Formação de professores para a EPT: perspectivas históricas e desafios contemporâneos. In: BRASIL. Ministerio da Educação. Instituto Nacional de Estudos e Pesquisas Educacionais (INEP). Formação de professores para ЕPт: Brasília, 26, 27 e 28 de setembro de 2006. Brasília: INEP, 2008a. p. 67-82.

MACHADO, L. Diferenciais inovadores na formação de professores para a educação profissional. Revista Brasileira de EPT, Brasília, DF, v. 1, n. 1, p. 8-22, jun. $2008 \mathrm{~b}$.

MACHADO, L. Organização da EPT por eixos tecnológicos. Linhas Críticas, Brasília, DF, v. 16, n. 30, p. 1-22, 2010.

MINAS GERAIS. Conselho Estadual de Educação. Resolução CEE/MG n. 397-1994. Consolida normas para Registro de Secretário de Escola e para Autorização do Exercício, a título precário, de Professor, de Diretor e de Secretário de Escola de $1^{\circ}$ e $2^{\circ}$ Graus. Aprovada em 16/09/1994. Publicada no Minas Gerais, em 01/10/1994. Disponível em: $<$ http://www.cee.mg.gov.br/resolucoes>. Acesso em: 22 jun. 2011.

SOUZA, A.N. Trajetórias de professores da educação profissional. Pro-Posições, Campinas, v. 16, n. 3 (48), p. 195-211, set./dez. 2005.

Recebido em 28 de junho de 2011.

Aprovado em 12 de agosto de 2011. 